\title{
Los factores de riesgo clásicos predicen la mortalidad de causa coronaria en los hombres jóvenes
}

Risk factors for coronary heart disease in men 18 to 39 years of age. Navas-Hacher EL, Colángelo L, Beam C et al. Ann Intern Med 2001; 134: 433-439.

\section{Objetivo}

Determinar la capacidad predictiva de los factores de riesgo mayores para predecir muerte de causa coronaria en hombres jóvenes.

\section{Diseño}

Estudio de cohorte prospectivo con 20 años de seguimiento.

\section{Lugar}

Este estudio se realizó en 84 empresas del área de Chicago que formaron parte del Proyecto de Prevención en la Industria de la Asociación de Cardiología de Chicago.

\section{Pacientes}

Se incorporaron 11016 hombres entre 18 y 39 años de edad al momento de su inclusión, con una edad promedio de 29.7 años, además se incluyeron otros 8955 hombres entre 40 y 59 años que constituyeron el grupo de referencia. El período de inclusión se extendió desde 1967 a 1973.

Medición de resultados principales

El punto final primario fue muerte debida a enfermedad coronaria.
Se realizó análisis multivariable* para demostrar la asociación entre los factores de riesgo y muerte. Se evaluaron los distintos factores de riesgo coronario para establecer su capacidad para predecir muerte coronaria en los jóvenes.

\section{Resultados}

La mortalidad en los jóvenes fue de 4/100p/20 años y la de origen coronario de 1.1/100p/20años. La muerte coronaria se asoció independientemente y significativamente con la edad, el nivel de colesterol, la presión sistólica y el tabaquismo.

Los $R^{*}$ fueron similares en jóvenes y en el grupo adulto de referencia salvo para el colesterol que fue mayor en los jóvenes ( 1.94 [IC 95\%, 1.65 a 2.28] vs 1.18 [IC, 1.12 a 1.25$]$ ).

\section{Conclusiones}

Los factores de riesgo mayores, hipercolesterolemia, hipertensión arterial y tabaquismo en los jóvenes, de igual manera que en los hombres adultos, se asocian con mayor mortalidad de origen coronario.

La demostración de la existencia de factores de riesgo modificables debería cambiar la conducta terapéutica en esta población.

\section{Comentario}

Existe suficiente información en la población de adultos y también en ancianos para asociar la hipertensión arterial, la hipercolesterolemia y el hábito tabáquico con mayor número de eventos y mayor mortalidad cardiovascular.

Apartir de estudios descriptivos, como el análisis de autopsias en jóvenes fallecidos en conflictos bélicos o en accidentes, se conoce la presencia de ateroesclerosis coronaria en edades tempranas de la vida 1.

En otros estudios de autopsias se observó que el desarrollo de lesiones coronarias en jóvenes era más frecuente entre los portadores de factores de riesgo 2 . Como es sabido, para apoyar la relación causa - efecto entre una exposición y una patología o evento se requiere conocer la relación temporal entre ambos factores de la ecuación. En este sentido, los estudios de corte transversal $^{*}$ mencionados no brindan información adecuada y se requieren estudios de seguimiento de cohortes donde se conoce la exposición y se vigila la aparición del evento. La literatura menciona dos estudios de este tipo, previos al que es motivo de este comentario; el estudio de Framingham que demuestra asociación entre la hipercolesterolemia y muerte total y cardiovascular pero está limitado a sólo 595 hombres menores de 40 años y ninguno menor de 30 años 3 . En el otro estudio de cohorte que incluye más de 1000 hombres jóvenes y también demuestra la asociación entre niveles elevados de colesterol y mortalidad cardíaca y total, el análisis se limitó, al igual que Framingham, a un único factor de riesgo que fue el colesterol 4 .

En el estudio de Chicago, el más numeroso hasta el presente y con un seguimiento del $99 \%$, no se puede descartar el sesgo de selección* pues la incorporación al estudio fue voluntaria y participaron sólo un $53 \%$ de los convocados. De todas maneras, la asignación del evento fue en desconocimiento de la exposición y esto garantiza mayor objetividad. La medición del factor de riesgo en una única oportunidad puede producir un error en la clasificación de los grupos y subestimar la asociación. La incorporación de otros factores de riesgo más noveles podría mejorar aún el modelo de predicción.

Ala luz de estos datos debería tomarse una conducta más activa en la corrección de los factores de riesgo en los hombres menores de 40 años.

Dr. César A. Belziti [ Unidad de Cuidados Intensivos Cardiológicos. Instituto del Corazón. Hospital Italiano de Buenos Aires ]

\section{Referencias}

1. McNamara JJ, Molor MA, Stremple JF et al. Coronary artery disease in combat casualties in Vietnam. JAMA1971; 216: 185-187.

2. Berenson GS, Srinivasan SR, Bao W et al. Association between múltiple cardiovascular risk factors and atherosclerosis in children and young adults. The Bogalusa Heart Study. N Engl J Med 1998, 338: 1650-1656

3. Anderson KM, Castelli WP, Levy D. Cholesterol and mortality. 30 years of follow up from the Framingham study. JAMA1987; 257: 2176-2180

4. Klag MJ, Ford DE, Mead LAet al. Serum colesterol in young men and subsequent cardiovascular disease, New Engl J of Med 1993; 328: 313-318 